\title{
The Usefulness of Evaluation of IgG Antibodies against Periodontopathic Bacteria for Prediction of Vascular Disease
}

Koichi Ishihara1', Shuichi Hagiwara1', Takashi Ogino², Masashi Morimura1 and Kiyohiro Oshima ${ }^{1 *}$

${ }^{1}$ Department of Emergency Medicine, Gunma University Graduate School of Medicine, Maebashi, Japan

${ }^{2}$ Emergency and Critical Care Center, National Hospital Organization Takasaki General Medical Center, Takasaki, Japan

\begin{abstract}
Background: The relationship between periodontopathic bacteria and cardiovascular disease has been shown in many studies. Additionally, it has been reported that the plasma antibody titer for periodontopathic bacteria is associated with the occurrence of coronary disease. In this study, we randomly evaluated the relation between the plasma antibody titer for periodontopathic bacteria and the existence of vascular diseases such as hypertension, stroke, and ischemic heart disease (IHD) in patients of the emergency room.
\end{abstract}

Methods: Sixty patients who had medical examination in the emergency department of our hospital from January to December 2009 were randomly and inconsecutively included. We measured the levels of immunoglobulin $(\mathrm{lg}) \mathrm{G}$ antibodies against Porphyromonas gingivalis (P. g.), Aggregatibacter actinomycetemcomitans (A. a.), Prevotella intermedia (P. i.), and Eikenella corrodens (E. C.) in patients' blood. Patients were divided into two groups; the positive group (even if one IgG antibody was significantly positive among four antibodies) and the negative group (negative for IgG antibody). The percentage of patients with vascular diseases (hypertension, stroke and IHD) was compared between the two groups.

Results: Vascular diseases found were as follows; hypertension $(n=11)$, stroke $(n=8)$, and ischemic heart disease $(n=5)$. There were 26 patients in the positive group and 34 patients in the negative group. The mean of age and the serum total protein in the positive group was significantly $(p>0.05)$ higher than in the negative group. The presence of vascular diseases excluding stroke was higher in the positive group, and hypertension and IHD separately, and all vascular diseases together were independently associated with the presence of antibodies against periodontopathic bacteria.

Conclusions: The presence of IgG antibodies against periodontopathic bacteria is significantly associated with the presence of vascular diseases. These results suggest that the evaluation of IgG antibodies for periodontopathic bacteria is useful for prediction of the presence of vascular disease.

Keywords: Vascular diseases; Periodontitis; Immunoglobulin

\section{Introduction}

Periodontal infection represents a favorable background for atherosclerosis and cardiovascular disease (CVD) [1,2]. Especially, the implication of periodontopathic bacteria such as Porphyromonas gingivalis (P. g.), Aggregatibacter actinomycetemcomitans (A. a.), Prevotella intermedia (P. i.), and Eikenella corrodens (E. c.) for systemic diseases has recently become an important topic in periodontal medicine. There are many reports of the association of these periodontopathic bacteria with CVD and stroke [3-10]. Periodontitis is associated with elevated levels of markers of inflammation that are indicators of CVD and stroke risk. Periodontal disease increases the systemic inflammatory response, which has been implicated in atherosclerosis and CVD, and markers of low grade inflammation have been consistently associated with a high risk of CVD [11]. However, there are few reports regarding the relationship between periodontopathic bacteria and the incidence of CVD in patients who do not have periodontal disease as the main medical complaint.

In this study, we randomly evaluated the relationship between the plasma antibody titers for periodontopathic bacteria and the existence of vascular diseases such as hypertension, stroke, and ischemic heart disease (IHD) in patients who visited or were transferred to emergency room of this hospital.

\section{Patients and Methods}

This study was approved by the Research Ethics Board at Gunma
University Hospital, and written consent was obtained from all patients or their appointed representatives.

Sixty patients who had medical examination in the emergency department of the hospital from January to December 2009 were prospectively analyzed in this study (patients were randomly selected and were not consecutive). The diseases, which were the reason why patients visited or were transferred to emergency room of this hospital, are shown in Table 1.

We used DEMECAL blood examination system (Sunstar Direct Dental Supply, Osaka, Japan) to measure the levels of immunoglobulin (Ig) $\mathrm{G}$ antibodies to periodontopathic bacteria such as P. g., A. a., P. i., and E. c. in the patients' blood. A feature of this system is that only a small volume of whole blood (about $50 \mu \mathrm{L}$ ) is required for

*Corresponding author: Kiyohiro Oshima, Department of Emergency Medicine, Gunma University Graduate School of Medicine, 3-39-22 Showamachi, Maebashi, Gunma 371-8511, Japan, Tel: +81-27-220-8540; E-mail: koshima@showa.gunma-u.ac.jp

Received December 10, 2013; Accepted January 20, 2014; Published January 26, 2014

Citation: Ishihara K, Hagiwara S, Ogino T, Morimura M, Oshima K (2014) The Usefulness of Evaluation of IgG Antibodies against Periodontopathic Bacteria for Prediction of Vascular Disease. J Cardiovasc Dis Diagn 2: 141. doi:10.4172/2329 9517.1000141

Copyright: $\odot 2014$ Ishihara K, et al. This is an open-access article distributed under the terms of the Creative Commons Attribution License, which permits unrestricted use, distribution, and reproduction in any medium, provided the original author and source are credited. 
Citation: Ishihara K, Hagiwara S, Ogino T, Morimura M, Oshima K (2014) The Usefulness of Evaluation of IgG Antibodies against Periodontopathic Bacteria for Prediction of Vascular Disease. J Cardiovasc Dis Diagn 2: 141. doi:10.4172/2329-9517.1000141

Page 2 of 4

\begin{tabular}{|c|c|}
\hline Disease & No. \\
\hline Multiple trauma & 8 \\
\hline AMI & 4 \\
\hline Cerebral infarction & 4 \\
\hline Gastroenteritis & 4 \\
\hline TIA & 4 \\
\hline Acute drug intoxication & 3 \\
\hline MD & 2 \\
\hline Appendicitis & 2 \\
\hline CPA & 2 \\
\hline Dizziness & 2 \\
\hline Esophageal cancer & 2 \\
\hline Epilepsy/seizure & 2 \\
\hline $\mathrm{HCC}$ & 2 \\
\hline Heatstroke & 2 \\
\hline Pneumonia & 2 \\
\hline Suffocation & 2 \\
\hline ALS & 1 \\
\hline Brain hemorrhage & 1 \\
\hline Brain tumor & 1 \\
\hline Drowning & 1 \\
\hline Ectopic pregnancy & 1 \\
\hline $\mathrm{G} \mathbb{H}$ & 1 \\
\hline Hyperventilation & 1 \\
\hline Lung cancer & 1 \\
\hline Migraine & 1 \\
\hline Myelitis & 1 \\
\hline Pancreatitis & 1 \\
\hline Pyelonephritis & 1 \\
\hline $\mathrm{SAH}$ & 1 \\
\hline Total & 60 \\
\hline
\end{tabular}

AMI: Acute Myocardial Infarction; TIA: Transient Ischemic Attack; HCC: Hepatocellula Carcinoma; AAD: Acute Aortic Dissection; CPA: Cardiopulmonary Arrest (The Causes of Cpas were Unknown in 2 Patients); GIH: Gastrointestinal Hemorrhage; SAH: Subarachnoid Hemorrhage; ALS: Amyotrophic Lateral Sclerosis

Table 1: Underlying diseases in all patients

the measurement of the levels of IgG antibodies to periodontopathic bacteria, and the results are obtained within 7 days of mailing the sample to the testing facility. Enzyme-linked immunosorbent assay (ELISA) method was used to measure the levels of IgG antibodies to bacteria. In the emergency room, blood was collected from all patients for routine blood cell counting and serum chemistry measurements and the remainder of that blood was used for the anti-bacterial antibody measurements. The analyses were performed blind to clinical status.

Patients were divided into two groups; the positive group (at least one IgG antibody was significantly positive among the four antibodies to P.g, A.a, P.i,, and E.c) and the negative group (sample was negative for all four antibodies). Inflammatory parameters such as white blood cell (WBC) counts and C-reactive protein (CRP), markers of state of nourishment such as total protein (TP) and albumin (Alb) levels in serum, aspartate aminotransferase (AST), alanine aminotransferase (ALT), lactate dehydrogenase (LDH), renal function such as blood urea nitrogen (BUN) and serum creatinine ( $\mathrm{sCr}$ ), and blood sugar (BS) levels were measured on arrival at the emergency room. The percentage

of patients with and without vascular diseases such as hypertension (diagnosed with hypertension and currently taking antihypertensive agents), stroke, and IHD including past history of these diseases was compared between the two groups.

\section{Statistical Analysis}

Data are presented as the mean \pm standard deviation (SD). MannWhitney $\mathrm{U}$ test was used to compare laboratory parameters between the two groups. Fisher's exact test was used to compare the percentage of patients with or without vascular disease between the two groups. Statistical analysis was performed with StatView software version 5.0 (Abacus, Berkeley, CA, USA). A $P$ value of less than 0.05 was interpreted to be statistically significant.

\section{Results}

The mean age of the patients was $62 \pm 21$ (range 4-95) years and there were 32 males and 28 females in the study. The oral evaluation was excluded from this study because we could not perform it in all cases. Vascular diseases found were as follows; hypertension $(\mathrm{n}=11)$, stroke $(n=8)$, and ischemic heart disease $(n=5)$.

There were 26 patients in the positive group and 34 patients in the negative group. In the positive group, IgG antibodies to P. g. were positive in all 26 patients (the mean of antibody titer: $29.8 \pm 52.4$, ranging 2.5 to 272.5 ), antibodies to $\mathrm{A}$. a. were positive in 4 (the mean of antibody titer: $1.5 \pm 0.5$, ranging 1.1 to 2.0 ), E. c. positive in 2 (the mean of antibody titer: $2.1 \pm 0.4$, ranging 1.8 to 2.3 ), and P.i. positive in 1 (antibody titer: 1.6). The comparisons of clinical characteristics between the two groups are shown in Table 2. Mean age in the positive group was significantly $(\mathrm{p}>0.05)$ higher than in the negative group (Table 3). Additionally, in the positive group, the mean serum total

\begin{tabular}{|c|c|c|c|}
\hline & $\begin{array}{c}\text { Negative group } \\
(n=34)\end{array}$ & $\begin{array}{l}\text { Positive group } \\
(n=26)\end{array}$ & $p$ value \\
\hline Age $(y / o)$ & $55 \pm 25$ & $70 \pm 12$ & 0.003 \\
\hline Male/Female ratio & $19 / 15$ & $13 / 13$ & 0.650 \\
\hline WBC $\left(x 103 / \mathrm{mm}^{3}\right)$ & $8.82 \pm 4.76$ & $8.90 \pm 5.42$ & 0.948 \\
\hline CRP (mg/di) & $1.4 \pm 3.1$ & $1.3 \pm 2.3$ & 0.955 \\
\hline TP (g/d1) & $6.4 \pm 1.1$ & $7.0 \pm 0.6$ & 0.014 \\
\hline Albumin (g/d1) & $3.6 \pm 0.8$ & $3.9 \pm 0.5$ & 0.072 \\
\hline AST (IWL) & $196 \pm 562$ & $64 \pm 160$ & 0.201 \\
\hline$\left.A L T^{\circ} \mathrm{U} / \mathrm{L}\right)$ & $102 \pm 245$ & $43 \pm 83$ & 0.200 \\
\hline $\left.\mathrm{LDH}^{\circ} \mathrm{U} / \mathrm{L}\right)$ & $623 \pm 1040$ & $289 \pm 249$ & 0.079 \\
\hline BUN (mg/di) & $21.4 \pm 18.7$ & $22.5 \pm 18.2$ & 0.821 \\
\hline Creatinine (mg/di) & $0.87 \pm 0.53$ & $0.88 \pm 0.67$ & 0.937 \\
\hline BS (mg/di) & $178 \pm 141$ & $143 \pm 47$ & 0.180 \\
\hline
\end{tabular}

WBC: White Blood Cell; CRP: C Reactive Protein; TP: Total Protein; AST: Asparatate Aminotransferase; ALT: Alanine Aminotransferase; LDH: Lactate Dehydrogenase; BUN: Blood Urea Nitrogen; BS: Blood Sugar

Table 2: The comparisons of clinical characteristics.

\begin{tabular}{|c|c|c|c|}
\hline & p value & Odds Ratio & $\begin{array}{c}\mathbf{9 5 \%} \\
\text { Interval }\end{array}$ \\
\hline Stroke & 0.7172 & 1.36 & $0.31-6.06$ \\
\hline Hypertension & 0.0437 & 4.59 & $1.08-19.55$ \\
\hline IHD & 0.0120 & 17.65 & $1.49-335.48$ \\
\hline All vascular disease & 0.0028 & 6.17 & $1.96-19.43$ \\
\hline
\end{tabular}

IHD: ischemic heart disease, all vascular diseases includes stroke, hypertension and IHD

Table 3: The results of Fisher's exact test. 
protein was significantly $(\mathrm{p}>0.05)$ higher than in the negative group (Table 3). There was no significant difference in the mean albumin concentration in serum between the two groups, although it was higher in the positive group. There were no significant differences in other parameters between the two groups.

In the positive group, there were 4 patients with stroke, 8 with hypertension, 5 with IHD, and totally 16 patients had vascular disease (including overlap). On the other hand, in the negative group there were 4 patients with stroke, 3 with hypertension, 0 with IHD, and totally 7 patients had vascular disease. Table 3 shows the results of Fisher's exact test regarding the comparison of the percentage of patients with or_without vascular disease between the two groups. The presence of vascular diseases excluding stroke was higher in the positive group, and hypertension and IHD separately, and all vascular diseases together (stroke, hypertension, and IHD) were independently associated with the positive antibody titer to periodontopathic bacteria.

\section{Discussion}

The diagnosis of periodontal disease is usually made by periodontal tissue evaluation and roentgenogram in general dental practice. However, these examinations only show the current state of tissue destruction caused by periodontal bacteria, and do not show the longterm results of invasion by periodontal bacteria in the living body. It was recently reported that the plasma antibody titer is a useful index of the long-term invasion of periodontopathic bacteria. Beck and co-workers showed that the plasma antibody titer for periodontopathic bacteria is associated with the occurrence of coronary disease [12]. However, there are few reports that evaluated this relationship in randomly chosen patients with diverse diseases with no complaint of periodontal disease. This study showed that presence of IgG antibodies to periodontopathic bacteria was significantly associated with hypertension, IHD, and vascular diseases. Our results agree with previous reports. On the other hand, there was no significant relationship with IgG antibodies to periodontopathic bacteria and stroke alone [13]. Also, Lee et al. argued that it was unclear whether cumulative periodontal disease was an independent risk factor for stroke [14]. The epidemiologic association between periodontitis and stroke is still controversial.

In this study, the mean age was significantly higher in the positive group than in the negative group. This result is reasonable because the oral hygiene generally deteriorates with advancing age. The oral hygiene status of the mucosal or denture surfaces also affects colonization by periodontopathic bacteria for complete denture wearers in elderly people [15]. It is therefore not surprising that poor oral hygiene is associated with higher levels of risk of cardiovascular disease [16]. There was a significant difference in the mean serum total protein between the two groups; however, this result probably has no clinical significance because the levels in both groups were almost within the normal range.

IgG antibody for P. g. was positive in all 26 patients in the positive group, and the positive rate for $\mathrm{P}$. g. was highest compared with presence of antibodies to other periodontopathic bacteria. P. g. is a gram-negative anaerobic bacterium to be a periodontal pathogen that causes severe periodontitis [7]. Additionally, P. g. has various roles in the cardiovascular system. Hokamura et al. reported that oral hematogenous spreading of P. g. is a causative event in the development of aortic hyperplasia in periodontitis patients and P. g. plays an important role in progression of intimal hyperplasia in the aorta [7]. Wada and his co-workers showed that the major characteristic of P. g. infection associated with aneurysms is smooth muscle proliferation in the distal aorta [8]. Our results also suggested the relation between $\mathrm{P}$. g. and vascular disease.

The pathophysiological mechanisms whereby periodontopathic bacteria influence the occurrence of CVD are still unclear. Some hypotheses have emerged. It was proposed that bacterial invasion causes production of toxins resulting in direct injury to biological tissues $[17,18]$. Other investigators reported that the initiation of platelet aggregation by platelet aggregation-associated protein (PAAP) may be a mechanism that promotes atherosclerosis development [19]. In addition, indirect activation of transcription factors through toll-like receptors was also proposed as a possibility [20]. Scientific evidence has not been found to prove a direct association between oral inflammation and atherosclerosis, and reliable markers are required that can accurately indicate the effect of periodontal disease on the condition of the arteries [21].

Some limitations of this study should be taken into account. This study was conducted in a single center with a small number of patients. Oral examination was not performed in all patients. Further studies are required to evaluate the relationship between periodontopathic bacteria and cardiovascular diseases.

\section{Conclusion}

In this study, the plasma IgG antibody titer against periodontopathic bacteria was evaluated in random patients with various underlying diseases in our emergency room. The results showed that presence of IgG antibodies to periodontopathic bacteria was significantly associated with the hypertension, IHD, and vascular diseases. These results suggest that the evaluation of IgG antibody for periodontopathic bacteria is useful for predicting the presence of vascular disease.

\section{References}

1. Beck JD, Pankow J, Tyroler HA, Offenbacher S (1999) Dental infections and atherosclerosis. Am Heart J 138: S528-533.

2. Niedzielska I, Janic T, Cierpka S, Swietochowska E (2008) The effect of chronic periodontitis on the development of atherosclerosis: review of the literature. Med Sci Monit 14: RA103-106.

3. Kuramitsu HK (2002) Periodontopathic bacteria and their potential involvement in atherosclerosis. Int J Oral Med Sci 1: 1-9.

4. Sakurai K, Wang D, Suzuki J, Umeda M, Nagasawa T, et al. (2007) High incidence of actinobacillus actinomycetemcomitans infection in acute coronary syndrome. Int Heart J 48: 663-675.

5. Chen YW, Iwai T, Umeda M, Nagasawa T, Huang Y, et al. (2007) Elevated IgG titers to periodontal pathogens related to Buerger disease. Int $\mathrm{J}$ Cardiol 122: 79-81.

6. Chen YW, Umeda M, Nagasawa T, Takeuchi Y, Huang Y, et al. (2008) Periodontitis may increase the risk of peripheral arterial disease. Eur $\mathrm{J}$ Vasc Endovasc Surg 35: 153-158.

7. Hokamura K, Umemura K (2010) Roles of oral bacteria in cardiovascular diseases--from molecular mechanisms to clinical cases: Porphyromonas gingivalis is the important role of intimal hyperplasia in the aorta. J Pharmacol Sci 113: 110-114.

8. Wada K, Kamisaki Y (2010) Roles of oral bacteria in cardiovascular diseasesFrom molecular mechanisms to clinical cases: Involvement of Porphyromonas gingivalis in the development of human aortic aneurysm. J Pharmacol Sci 113 115-119.

9. Figuero E, Sánchez-Beltrán M, Cuesta-Frechoso S, Tejerina JM, del Castro JA, et al. (2011) Detection of periodontal bacteria in atheromatous plaque by nested polymerase chain reaction. J Periodontol 82: 1469-1477.

10. Sfyroeras GS, Roussas N, Saleptsis VG, Argyriou C, Giannoukas AD (2012) Association between periodontal disease and stroke. J Vasc Surg 55: 11781184 
Citation: Ishihara K, Hagiwara S, Ogino T, Morimura M, Oshima K (2014) The Usefulness of Evaluation of IgG Antibodies against Periodontopathic Bacteria for Prediction of Vascular Disease. J Cardiovasc Dis Diagn 2: 141. doi:10.4172/2329-9517.1000141

11. Danesh J, Wheeler JG, Hirschfield GM, Eda S, Eiriksdottir G, et al. (2004) C-reactive protein and other circulating markers of inflammation in the prediction of coronary heart disease. N Engl J Med 350: 1387-1397.

12. Beck JD, Eke P, Heiss G, Madianos P, Couper D, et al. (2005) Periodonta disease and coronary heart disease: a reappraisal of the exposure. Circulation 112: $19-24$.

13. Howell TH, Ridker PM, Ajani UA, Hennekens CH, Christen WG (2001) Periodontal disease and risk of subsequent cardiovascular disease in U.S. male physicians. J Am Coll Cardiol 37: 445-450.

14. Lee HJ, Garcia RI, Janket SJ, Jones JA, Mascarenhas AK, et al. (2006) The association between cumulative periodontal disease and stroke history in older adults. J Periodontol 77: 1744-1754

15. Yasui M, Ryu M, Sakurai K, Ishihara K (2012) Colonisation of the oral cavity by periodontopathic bacteria in complete denture wearers. Gerodontology 29: e494-502.

16. de Oliveira C, Watt R, Hamer M (2010) Toothbrushing, inflammation, and risk of cardiovascular disease: results from Scottish Health Survey. BMJ 340: c2451.
17. Haraszthy VI, Zambon JJ, Trevisan M, Zeid M, Genco RJ (2000) Identification of periodontal pathogens in atheromatous plaques. J Periodontol 71: 15541560.

18. Stelzel M, Conrads G, Pankuweit S, Maisch B, Vogt S, et al. (2002) Detection of Porphyromonas gingivalis DNA in aortic tissue by PCR. J Periodontol 73: 868-870.

19. Herzberg MC, Weyer MW (1998) Dental plaque, platelets, and cardiovascular diseases. Ann Periodontol 3: 151-160.

20. Hajishengallis G, Sharma A, Russell MW, Genco RJ (2002) Interactions of oral pathogens with toll-like receptors: possible role in atherosclerosis. Ann Periodontol 7: 72-78

21. Niedzielska I, Janic T, Cierpka S, Swietochowska E (2008) The effect of chronic periodontitis on the development of atherosclerosis: review of the literature. Med Sci Monit 14: RA103-106. 